\title{
Characteristics of sausages affected by reduction and partial substitution of pork backfat with pre-emulsified soybean oil
}

\author{
N. Prabsangob \\ Department of Product Development, Faculty of Agro-Industry, Kasetsart University, Bangkok 10400, \\ Thailand
}

\section{ORIGINAL RESEARCH PAPER}

Received: June 05, 2020 - Accepted: October 06, 2020

Published online: February 12, 2021

(C) 2020 Akadémiai Kiadó, Budapest

\section{ABSTRACT}

Improvement of nutritive profile of pork sausages was performed by fat reduction and partial substitution of backfat with soybean oil (SBO). The control sausage was made from pork backfat. For the studied samples, SBO in native and pre-emulsified forms was used for partial substitution of backfat at $25 \%$ (by wt of backfat) to produce sausages with various fat contents $(30,20$, and $10 \%)$. Discontinuity of protein matrix could be observed with increasing fat content, especially for addition of pork backfat. Improvement on product stability could be achieved using SBO, especially pre-emulsified form, to partially replace animal fat. Better dispersibility of the SBO droplets through the meat matrix compared to backfat globules was suggested by the greater continuity in the microstructure of the sausages with SBO. For the sausages supplemented with pre-emulsified SBO, the non-meat protein used as emulsifier could further strengthen the protein network, thereby resulting in enhanced product stability and retained textural attributes of the sausages. The fish protein isolate presently employed as emulsifier to prepare SBO emulsion could be promisingly used to produce more nutritive sausages by providing adequate stability.

\section{KEYWORDS}

fat reduction, fish protein isolate, fat substitution, pre-emulsification, sausages, soybean oil

\footnotetext{
*Corresponding author. E-mail: faginrpr@ku.ac.th
} 


\section{INTRODUCTION}

Emulsified meat products are widely consumed due to their appreciated taste and sensory characteristics as well as being a good source of nutritive compounds, e.g., proteins, essential amino acids, vitamins, and minerals. Nevertheless, the emulsified meat products always have high fat content, typically $20-30 \%$ of animal fats with abundant cholesterol and saturated fatty acid (SFA) (Herrero et al., 2014). Awareness on consumption of high fat food products, especially with high contents of SFA, has been continuously increasing due to some related health threatening effects, such as obesity, hypertension, and cardiovascular disease (Ozvural and Vural, 2008). In the last decade, improvement on nutritive profile of meat products has been implemented by reducing fat content as well as using vegetable oils with high content of polyunsaturated fatty acid (PUFA) to partially replace animal fat. Several PUFA rich oils, e.g. canola oil (Alejandre et al., 2019) and soybean oil (SBO) (Cheetangdee, 2017a,b), have been used to replace animal fat in comminuted meat products.

Fat has several functional roles in meat products, e.g. providing desirable oral sensation and favourable texture characteristic. Reduction of fat influences stability and quality of emulsified meat products (Paglarini et al., 2019). Partial substitution of animal fat using alternative oils also affects characteristics of the product due to their considerably different properties in consistency, colour, and flavour. Pre-emulsification, a process of preparing oil-in-water emulsion prior to be incorporated in a meat product, is a practical means to add vegetable oils into comminuted meat products. The non-meat proteins used to stabilise pre-emulsified emulsions play important role in enhancing the stability of the product. In this work, fish protein isolate (FPI) prepared from a yellow stripe trevally (Selaroides leptolepis) was employed to stabilise pre-emulsified SBO, chosen because of its good profile of essential amino acid (Cheetangdee, 2017a). Moreover, potent emulsifying ability of FPI in prepared emulsified meat products was previously suggested (Cheetangdee, 2017b). Nevertheless, utilisation of FPI in emulsified meat product with fat reduction has not been elucidated yet. The present work aimed to improve the nutritive profile of the sausages by reducing fat content and increasing amount of PUFA, and to elucidate the effect of FPI stabilised SBO emulsion on the characteristics of sausages.

\section{MATERIALS AND METHODS}

\subsection{Materials}

Fresh pork shoulder meat, pork backfat, the yellow stripe trevally (with size of $20 \mathrm{fish} / \mathrm{kg}$ ), and SBO were bought from a local market (Songkhla, Thailand). After washing, all visible fat and connective tissue was trimmed from the pork meat. The trimmed meat and backfat were comminuted and kept in plastic bags individually at $-18{ }^{\circ} \mathrm{C}$ for not more than 2 months before use. The FPI was prepared with a $\mathrm{pH}$-shift method according to the procedure of Cheetangdee (2017a). Sodium nitrite and sodium tripolyphosphate were products of Ajax FineChem (Auckland, New Zealand) and Aditya Birla Chemicals (Samutprakarn, Thailand), respectively. Seasoning was kindly provided by Flavor Force Co., Ltd (Bangkok, Thailand).

\subsection{Preparation of sausages with $\mathrm{SBO}$ inclusion at varying fat contents}

The sausages were prepared with fat contents of 30,20 , and $10 \%$. The control sausages (Ct) were made from backfat, whereas SBO inclusion was performed for the studied samples at 25\% 
(by wt of backfat) in a form of native $(n-\mathrm{SBO})$ or pre-emulsion (pre-SBO). The pre-SBO was prepared using FPI (at the concentration of $2 \%$ ) as emulsifier at the oil fraction of 0.5 as per the method of Cheetangdee (2017a). Protein content in all samples was fixed at $15 \%$ by calculating from the protein present in lean meat, backfat, and FPI. Moisture content was kept constantly for all samples at 70\%, and the required amount of water subtracted from the moisture contents present in lean meat, backfat and pre-SBO was additionally added. Formulation of the sausage is shown in Table 1.

The sausages were prepared according to the method of Cheetangdee (2017b) with some modifications. Briefly, the comminuted meat and backfat were kept at $4{ }^{\circ} \mathrm{C}$ overnight before use. The additives were dissolved in the added water at $4{ }^{\circ} \mathrm{C}$ on the day of use. The lean meat was chopped using a blender (MK-77, National, Tokyo, Japan) at a low speed for $30 \mathrm{~s}$. A half of backfat (or SBO) and the additive solution were added, before further chopping for $1 \mathrm{~min}$. Then, the rest of backfat (or SBO) was added and the mixture was chopped for $1 \mathrm{~min}$. After standing for $1.5 \mathrm{~min}$ for protein extraction, the mixture was finally chopped for $2 \mathrm{~min}$. The temperature was kept at lower than $12{ }^{\circ} \mathrm{C}$ throughout the process. The batter was stuffed in a cellulose casing (15 $\mathrm{mm}$ in diameter), heated $\left(75 \pm 2{ }^{\circ} \mathrm{C}\right.$ for $\left.30 \mathrm{~min}\right)$, and cooled until core temperature reached $25^{\circ} \mathrm{C}$. Twenty sausages ( $c a .500 \mathrm{~g}$ of meat batter) were produced in each batch, and two batches were prepared separately for each formulation.

The sausages were kept at $4{ }^{\circ} \mathrm{C}$ in a polyethylene bag packed without vacuum for no more than 2 weeks, before further analyses.

\subsection{Sausages characterisation}

Cooking loss and water holding capacity (WHC): Cooking loss and WHC of the sausages were quantified after heating $\left(80{ }^{\circ} \mathrm{C}, 20 \mathrm{~min}\right)$ and centrifugation $\left(1,000 \times g, 10 \mathrm{~min}\right.$ at $\left.4{ }^{\circ} \mathrm{C}\right)$, respectively (Hur et al., 2008).

Texture profile analysis: The sausages were cut in a cylinder shape (5 pieces for each sample) with diameter of $10 \mathrm{~mm}$ and length of $250 \mathrm{~mm}$. The texture analyser (TA-XT2 Stable Micro

Table 1. Formulation of sausages with different fat types and amounts

\begin{tabular}{lcccccc}
\hline Treatment & $\begin{array}{c}\text { Pork meat } \\
(\%)\end{array}$ & $\begin{array}{c}\text { Pork backfat } \\
(\%)\end{array}$ & $\begin{array}{c}n \text {-SBO } \\
(\%)\end{array}$ & $\begin{array}{c}\text { pre-SBO } \\
(\%)\end{array}$ & $\begin{array}{c}\text { Water } \\
(\%)\end{array}$ & $\begin{array}{c}\text { Total fat content } \\
(\%)\end{array}$ \\
\hline $\mathrm{Ct}$ & 48.1 & 30.0 & - & - & 19.9 & 30 \\
$n$-SBO & 48.6 & 22.2 & 7.4 & - & 20.1 & \\
pre-SBO & 47.7 & 22.3 & - & 14.9 & 13.2 & \\
$\mathrm{Ct}$ & 54.1 & 21.8 & - & - & 21.9 & 20 \\
$n$-SBO & 54.3 & 16.2 & 5.4 & - & 21.8 & \\
pre-SBO & 53.7 & 16.3 & - & 10.9 & 17.0 & \\
Ct & 61.2 & 12.0 & - & - & 24.4 & 10 \\
$n-$ SBO & 61.3 & 9.0 & 3.0 & - & 24.3 & \\
pre-SBO & 61.0 & 9.0 & - & 6.0 & 21.6 & \\
\hline Protein, & & & & & &
\end{tabular}

Protein, fat, and moisture contents in lean meat were $24.0,1.3$, and $72.9 \%$, respectively. Protein, fat, and moisture contents in pork backfat were 3.1, 83.3, and 10.9\%, respectively. Protein content of FPI was $84.7 \%$. All formulae contained the mixture of $\mathrm{NaCl}(1.5 \%)$, sugar $(0.5 \%)$, sodium tripolyphosphate $(0.2 \%)$, seasoning powder $(0.1 \%)$, sodium nitrite $(0.01 \%)$, and monosodium glutamate $(0.08 \%)$. 
System, Surrey, UK) equipped with a cylindrical probe (diameter $5 \mathrm{~mm}$ ) was used. The samples were compressed to $50 \%$ of their original height at a cross speed of $5 \mathrm{~mm} \mathrm{~s}^{-1}$ for two cycles at ambient temperature. The texture attributes involving hardness, cohesiveness, chewiness, springiness, and gumminess were quantified.

Microstructure: The sausage microstructure was examined using a scanning electron microscope (FEI Quanta 400, FEI Europe BV, Eindhoven, the Netherlands) as per the method of Jiang and Xiong (2013) with a slight modification. A cubic sample $\left(2.5 \times 2.5 \times 2.5 \mathrm{~mm}^{3}\right)$ was fixed by glutaraldehyde (2\%) for $24 \mathrm{~h}$ at $4{ }^{\circ} \mathrm{C}$. Dehydrating was performed using the series of ethanol solutions with concentrations of $50,70,80$, and $90 \%$ once each for $10 \mathrm{~min}$, and twice in absolute ethanol for $10 \mathrm{~min}$. The samples were introduced to a critical point dryer (Balzer model CPD 030, Liechtenstein, Switzerland) using $\mathrm{CO}_{2}$ as transition fluid and sputter-coated with gold. The microstructure of the samples was observed at an accelerating voltage of $15 \mathrm{kV}$.

Colour: The sausages were cut fresh and the colour of cross-section was evaluated using a HunterLab colorimeter (ColorFlex, Hunter Associates Laboratory Inc., VA, USA). Colour parameter was reported through CIE system as $L^{*}, a^{*}$ and $b^{*}$.

\subsection{Statistical analysis}

All experiments were run in triplicate, and mean values with standard deviations were reported. Statistical analysis was performed by analysis of variance using Duncan's multiple range tests (SPSS for Windows: SPSS Inc., Chicago, IL, USA) at a 95\% confidence level.

\section{RESULTS AND DISCUSSION}

\subsection{Stability of the sausages}

Stability of the sausages was determined as cooking loss and WHC (Fig. 1). When fat content increased, cooking loss tended to increase as well, suggesting less stability of the sausages with higher fat content. At the same fat contents, the lowest cooking loss was found for the pre-SBO $(P \leq 0.05)$, implying highest stability of the sausages incorporated with pre-SBO compared to the others. To elucidate better stability of the sausages with lowered fat content, especially for the samples added with pre-SBO, the microstructure of the samples was further studied.

At a comparable fat content, higher WHC was found for the sausages added with pre-SBO $(P \leq 0.05)$. This suggested a better stability of the sausages added with pre-SBO, which was in correlation with the reduced cooking loss. As a result of fat reduction, lowered WHC of the Ct was noticeable when fat content was reduced to $20 \%(P \leq 0.05)$, whereas fat reduction seemed to have no effect on WHC of the sausages substituted with $n$-SBO and pre-SBO $(P>0.05)$. This tendency implied higher water trapping ability of the sausages incorporated with SBO instead of pork fat, which is in accordance with lower cooking loss of the former sausages (Fig. 1A). Due to higher PUFA content, SBO might possess better water trapping ability compared to pork backfat dominantly consisting of SFA. Improvement on water retention of the frankfurters could be achieved when sesame oil was employed to substitute backfat (Zhuang et al., 2016).

The highest stability was obtained for the sausages added with pre-SBO, which might be attributed to a presence of non-meat proteins employed as emulsifier to prepare pre-SBO. As a result of heating at sausage preparation, partial denaturation of FPI molecules, available either on the interfacial areas or in the aqueous phase of the emulsion, could be expected 


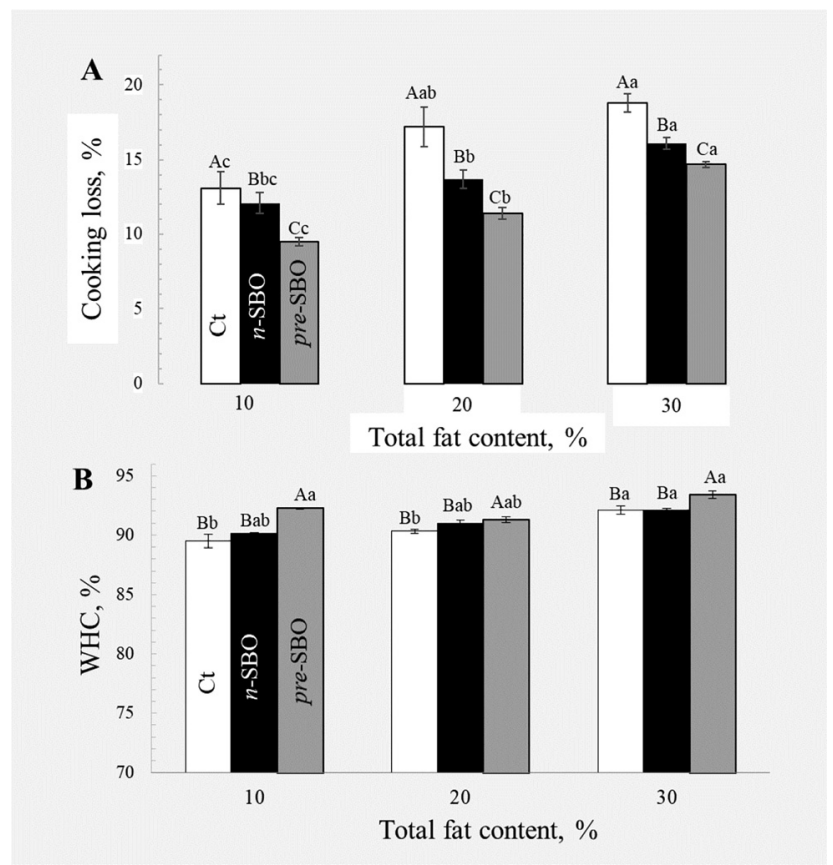

Fig. 1. Effect of fat content on A: cooking loss and B: WHC of the sausages. In each subfigure, the capital letters indicate significant difference at the same total fat level, and the small letters indicate significant difference at the same fat type $(P>0.05)$. Ct: control sausage, $n$-SBO: native soybean oil; pre-SBO: pre-emulsified soybean oil

(Cheetangdee, 2017a). This effect might enhance the interaction between protein molecules, promoting meat matrix stability. Formation of interfacial protein films is a predominant mechanism to stabilise fat globules and to enhance stability of the emulsified meat matrix (Cheetangdee, 2017b). Better water and fat binding capacity of the sausages were also observed when pork backfat was partially replaced with canola oil, especially in pre-emulsified form (Chen et al., 2020).

\subsection{Texture of the sausages}

Hardness, chewiness, gumminess, and springiness of the sausages tended to increase with increased fat content (Fig. 2). This trend was in accordance with other studies for meat batter (Zhuang et al., 2016) and Bologna sausage (Paglarini et al., 2019). Higher hardness of the sausages with increased fat content was accompanied with higher cooking loss (Fig. 1). Higher cooking loss indicated lower ability of the meat matrix to trap water and fat during protein denaturation, resulting in higher hardness of the product (Chen et al., 2020). However, contradictory behaviour was observed for the sausages supplemented with SBO. This might be explained by other mechanisms.

At a comparable fat content, better retained texture was found for the sausages supplemented with SBO, especially for the pre-SBO added samples, whereas higher cooking loss was reported 

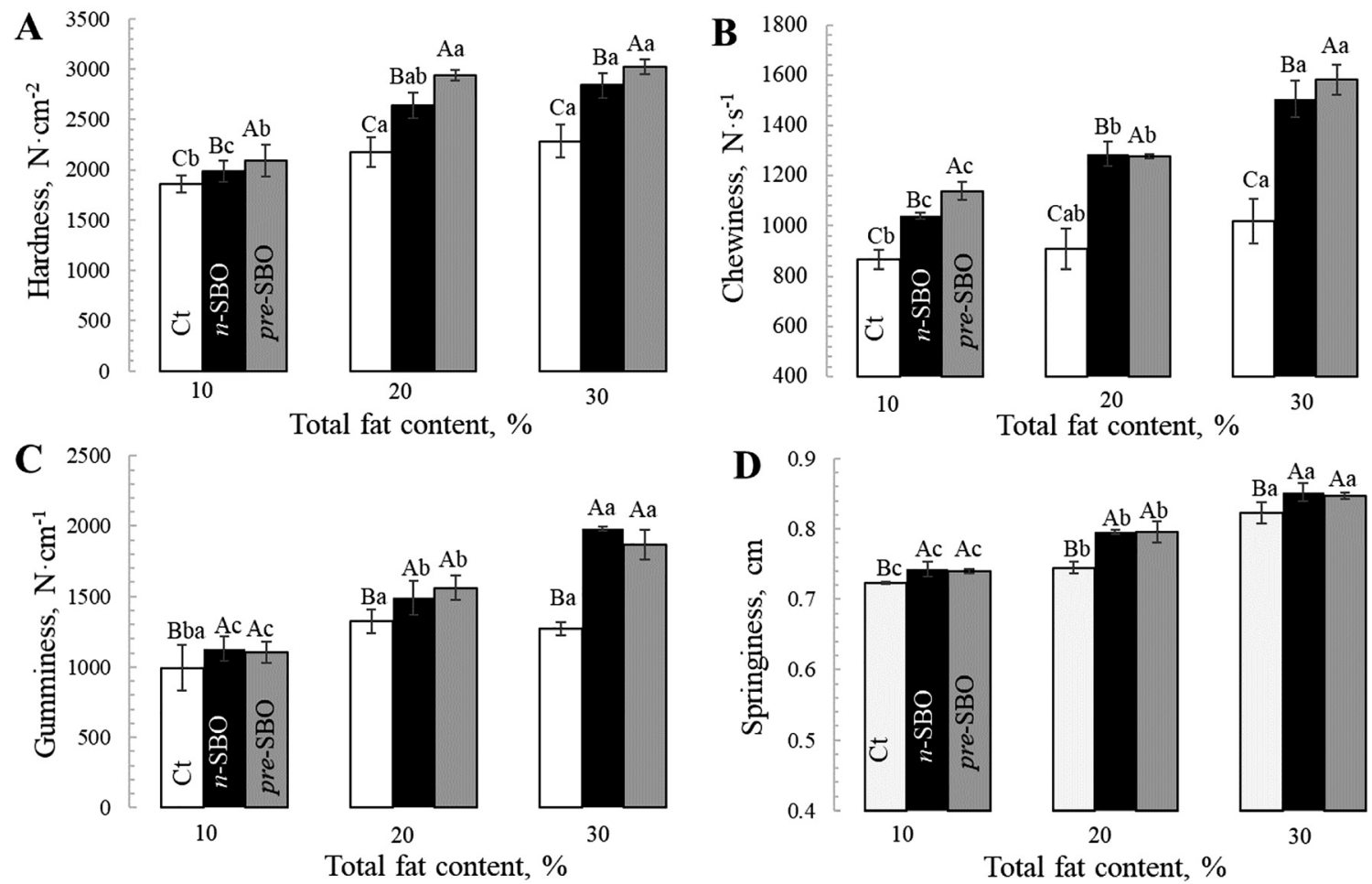

Fig. 2. Effect of fat content on A: hardness, B: chewiness, C: gumminess, and D: springiness of the sausages. In each subfigure, the capital letters indicate significant difference at the same total fat level, and the small letters indicate significant difference at the same fat type $(P>0.05)$. Ct: control sausage, $n$-SBO: native soybean oil; pre-SBO: pre-emulsified soybean oil 
for the Ct. Introducing oil through pre-emulsification means might enhance fat/oil binding capacity, thereby reinforcing matrix stability of meat products (Asuming-Bediako et al., 2014). The least retained structural texture of the $\mathrm{Ct}$, moreover, might be due to larger size of backfat globules compared to SBO droplets. With smaller size, larger interfacial areas of SBO drops might allow higher surface denaturation of the adsorbed protein residues. This effect might facilitate interactions between protein molecules, thereby enhancing meat matrix stability (Barbut and Marangoni, 2019). Furthermore, the highest hardness observed for the pre-SBO added sausages $(P \leq 0.05)$ might be due to the ability of FPI to strengthen protein network, due to the interactions between partially denatured FPI molecules induced by heating during sausage preparation (Cheetangdee, 2017b).

\subsection{Microstructure of the sausages}

Total fat content crucially affected microstructure of the sausages, a denser network could be obviously seen for the samples with lower fat contents (Fig. 3). It should be remembered that the total protein content was set constantly at $15 \%$ in this study. With higher fat content, less amount of protein to cover surfaces of the fat globules might be available, so restricted interaction between protein and fat can be assumed. This might lead to discontinuity of the threedimensional network, suggested by the presence of irregular shaped and large sized cavities in the matrix of the sausages with higher fat contents. Degree of interaction between proteins and fats highly affected continuity of meat matrix, thereby determining stability of the product

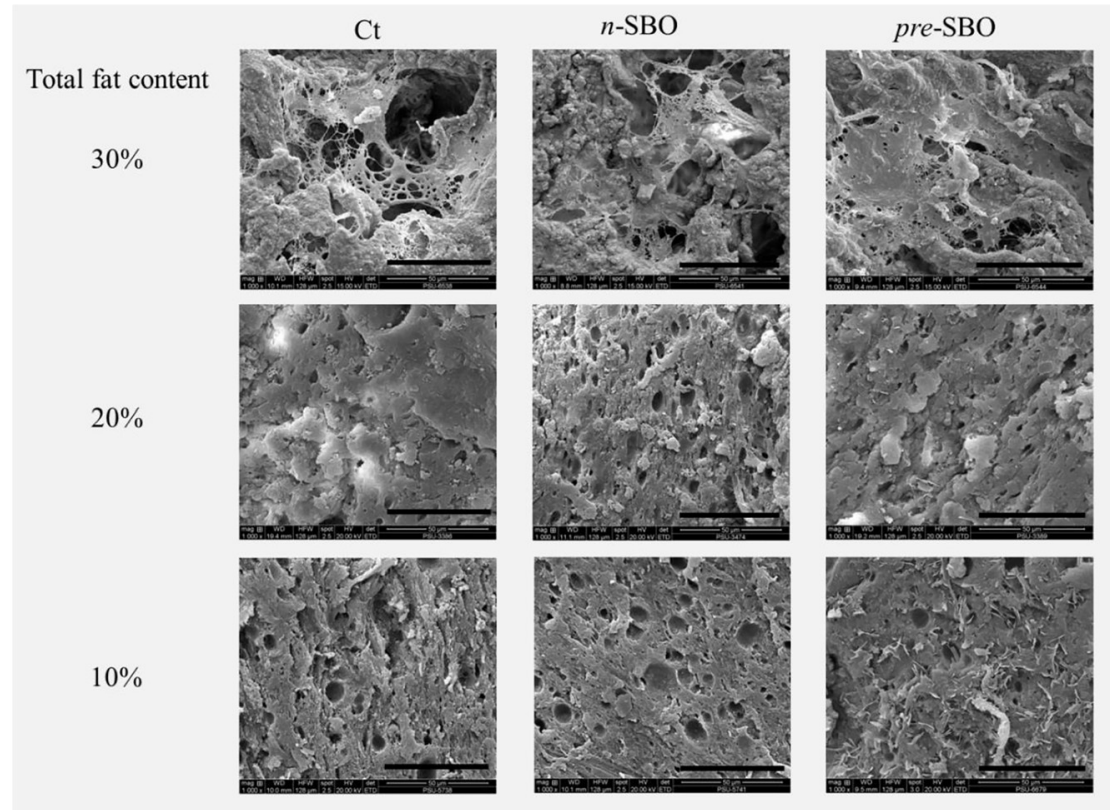

Fig. 3. Microstructure $(1,000 \times)$ of the sausages with SBO supplementation at different total fat contents. The bars in each subfigure represent $50 \mu \mathrm{m}$ length. Ct: control sausage, $n$-SBO: native soybean oil; pre-SBO: pre-emulsified soybean oil 
(Alejandre et al., 2019). Formation of a coherent matrix with small voids and channels could restrict fluid migration from the protein matrix (Youssef et al., 2011). With looser microstructure of the sausages with higher fat content, higher cooking loss is expected (Fig. 1).

At a comparable fat content, better continuity microstructure was found for the sausages supplemented with SBO and pre-SBO, indicated by the presence of fewer and smaller voids compared to the Ct. During chopping, the liquid stage of SBO might provide a larger number of small sized voids with closer packing than animal fat with harder nature (Youssef et al., 2011), resulting in denser protein network formation.
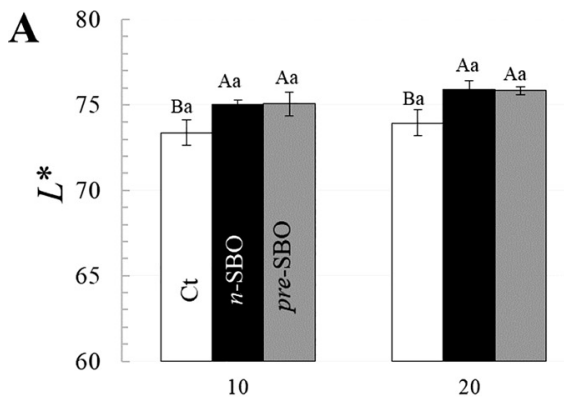

Total fat content, $\%$
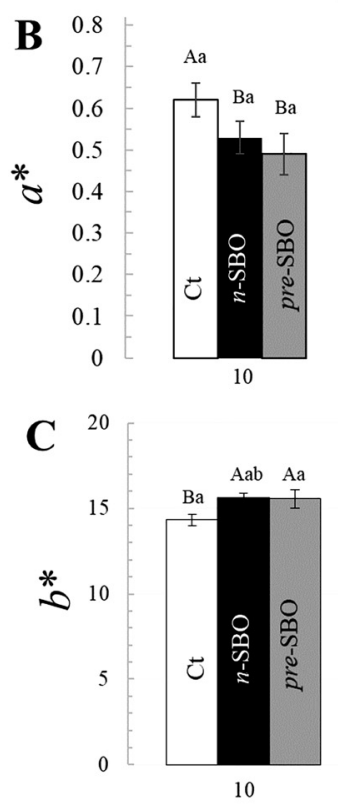

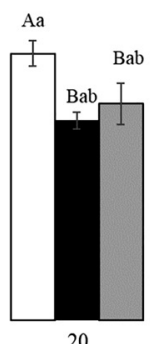

Total fat content, $\%$

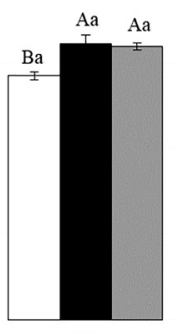

20

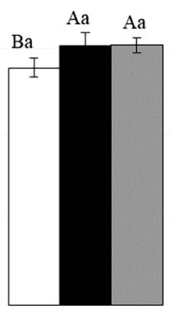

30

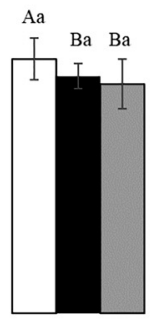

30

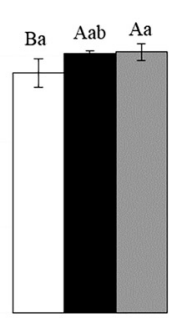

30

Total fat content, $\%$

Fig. 4. Effect of fat content on A: $L^{*}, \mathbf{B}: a^{*}$, and $\mathbf{C}: b^{*}$ of the sausages. In each subfigure, the capital letters indicate significant difference at the same total fat level, and the small letters indicate significant difference at the same fat type $(P>0.05)$. Ct: control sausage, $n$-SBO: native soybean oil; pre-SBO: pre-emulsified soybean oil 
The most dense and smooth protein network could be observed for the sausages supplemented with pre-SBO, which was accompanied with lower cooking loss (Fig. 1) and retained texture (Fig. 2). Formation of heat-induced gel of FPI might enhance matrix stability (Alejandre et al., 2019). Better retained texture was reported for the Bologna added with pre-emulsified SBO compared to animal fat, supposedly due to better embedding of the oil drops in the gel-network of the product (Gao et al., 2015). This behaviour was also found for beef batters when preemulsified canola oil was used to partially substitute beef fat (Alejandre et al., 2019), and for sausages when pork backfat was partially replaced with pre-emulsified canola oil (Chen et al., 2020).

\subsection{Colour of the sausages}

Fat content generally had no effect on colour $(P>0.05)$, but the introduced fat type crucially influenced the colour of the sausages (Fig. 4). Higher $L^{*}$ was observed for the sausages supplemented with SBO than for $\mathrm{Ct}(P \leq 0.05)$. This might be due to the smaller size of SBO drops with larger surface areas than animal fat globules, thereby allowing higher light reflection (Youssef and Barbut, 2011). Lowered redness of the SBO added sausages observed in this work $(P \leq 0.05)$ was in agreement with values measured for meat batters (Alejandre et al., 2019) and frankfurters (Chen et al., 2020) when animal fat was partially replaced with vegetable oils. Higher $b^{*}$ of the sausages supplemented with SBO was reported compared to Ct $(P \leq 0.05)$, supposedly because of the yellow note of SBO. Increasing of $b^{*}$ by substitution of animal fat with vegetable oils was also found in meat patties (Barbut and Marangoni, 2019).

As a result of SBO inclusion, fatty acid composition of the sausages significantly changed. PUFA content increased by ca. 50-55\%, whereas the SFA content decreased by ca. 11-13\% compared to the $\mathrm{Ct}$ sausages made from pork backfat (data in the Supplemented file). This behaviour was expected due to the major presence of linolenic acid of SBO.

\section{CONCLUSIONS}

Amount and type of introduced fat highly affected the characteristics of sausages in term of matrix formation. With restricted protein content, higher fat content led to discontinuity in the protein matrix, resulting lower stability of the sausages. Partial substitution of pork backfat with SBO could improve product stability, primarily when SBO was added in pre-emulsified form. This was due to the better ability of the SBO droplets to be embedded in the meat matrix compared to the large size and high consistency of backfat globules. Moreover, FPI used as emulsifier for pre-SBO preparation could strengthen the protein network, so further improved stability of the sausages. This work suggests that FPI can be promisingly employed as natural additive to produce nutritive sausages with lower fat and higher PUFA contents effectively. For production of fat-reduced sausage with pre-SBO inclusion, further experiments on chemical changes during storage, especially on lipid oxidation, and sensory acceptance studies should be performed.

\section{ACKNOWLEDGEMENT}

This work was supported by the Thailand government budget. 


\section{SUPPLEMENTARY MATERIAL}

Supplementary data to this article can be found online at https://doi.org/10.1556/066.2020.00162.

\section{REFERENCES}

Alejandre, M., Astiasarán, I., Ansorena, D., and Barbut, S. (2019). Using canola oil hydrogels and organogels to reduce saturated animal fat in meat batters. Food Research International, 122: 129-136.

Asuming-Bediako, N., Jaspal, M.H., Hallett, K., Bayntun, J., Baker, A., and Sheard P.R. (2014). Effects of replacing pork backfat with emulsified vegetable oil on fatty acid composition and quantity of UK-style sausage. Meat Science, 96: 187-194.

Barbut, S. and Marangoni, A. (2019). Organogels use in meat processing - Effects of fat/oil type and heating rate. Meat Science, 149: 9-13.

Cheetangdee, N. (2017a). Characteristic of sausages as influenced by partial replacement of pork back-fat using pre-emulsified soybean oil stabilized by fish proteins isolate. ANRES, 51: 310-318.

Cheetangdee, N. (2017b). Effect of partial replacement of porcine fat with pre-emulsified soybean oil using fish protein isolate as emulsifier on characteristic of sausage. Journal of Food Science and Technology, 54: 1901-1909.

Chen, Y., Jia, X., Sun, F., Jiang, S., Liu, H., Liu, Q., and King, B. (2020). Using a stable pre-emulsified canola oil system that includes porcine plasma protein hydrolysates and oxidized tannic acid to partially replace pork fat in frankfurters. Meat Science, 160: 107968.

Gao, X., Zhang, W., and Zhou, G. (2015). Emulsion stability, thermo-rheology and quality characteristics of ground pork patties prepared with soy protein isolate and carrageenan. Journal of the Science of Food and Agriculture, 95: 2832-2837.

Herrero, A.M., Carmona, P., Jinéz-Colmenero, F., and Ruiz-Capillas, C. (2014). Polysaccharide gels as oil bulking agents: Technological and structural properties. Food Hydrocolloid, 36: 374-381.

Hur, S.J., Jin, S.K., and Kin, S. (2008). Effect of extra virgin olive oil substitution for fat on quality of pork patty. Journal of the Science of Food and Agriculture, 88: 1231-1237.

Jiang, J. and Xiong, Y.L. (2013). Extreme $\mathrm{pH}$ treatments enhance the structure-reinforcement role of soy protein isolate and its emulsions in pork myofibrillar protein gels in the presence of microbial transglutaminase. Meat Science, 93: 469-476.

Ozvural, E.B. and Vural, H. (2008). Utilization of interesterified oil blends in the production of frankfurters. Meat Science, 78: 211-216.

Paglarini, C.S., Furtado, G.F., Honório, A.R., Mokarze,l L., Vidal, V.A.S., Ribeiro, A.P., Cunha, R.L., and Pollonio, M.A.R. (2019). Functional emulsion gels as pork back fat replacers in Bologna sausage. Food Structure, 20: 100105.

Youssef, M.K. and Barbut, S. (2011). Fat reduction in comminuted meat products-effects of beef fat, regular and pre-emulsified canola oil. Meat Science, 87: 356-360.

Youssef, M.K., Barbut, S., and Smith, A. (2011). Effects of pre-emulsifying fat/oil on meat batter stability, texture and microstructure. International Journal of Food Science \& Technology, 46: 1216-1224.

Zhuang, X., Han, M., Kan, G.Z., Wang, K., Bai, Y., Xu, X.L., and Zhou, G. (2016). Effects of the sugarcane dietary fiber and pre-emulsified sesame oil on low-fat meat batter physicochemical property, texture, and microstructure. Meat Science, 113: 107-115. 